\title{
Using the SGDA Framework to Design and Evaluate Research Games
}

Simulation \& Gaming

$1-30$

(C) The Author(s) 2018 Article reuse guidelines: sagepub.com/journals-permissions DOI: 10.1 I77/1046878|18808826 journals.sagepub.com/home/sag

@SAGE

\author{
David Geerts',2, Marije Nouwen',2, \\ Evert van Beek ${ }^{3}$, Karin Slegers ${ }^{1,4}$, \\ Fernanda Chocron Miranda ${ }^{1,5}$, \\ and Lizzy Bleumers ${ }^{2,6}$
}

\begin{abstract}
Background. Several $\mathbf{H C l}$ researchers have started to use game design elements in their research to create playful methods for involving end-users in design. Similar to serious games, such research games serve a dual purpose: I) to create an enjoyable experience for research participants, and 2) to collect user insights to inform the design process.

Aim. We propose that the Serious Game Design Assessment (SGDA) Framework, that evaluates both a game's enjoyable purposes and its serious purposes, may be a valuable tool in assessing and developing research games. In this article, we apply the SGDA Framework to three existing research games, one involving train passengers in assessing potential future user experiences, one involving hospital staff in ideation for wearable technology, and one involving TV viewers in ideation for future video watching scenarios.

Conclusion. The assessment of the three research games suggests that the framework is indeed applicable to research games and may, as such, provide $\mathbf{H C l}$ researchers with clear guidance when creating new research games.
\end{abstract}

\footnotetext{
'KU Leuven, Belgium

2IMEC, Belgium

${ }^{3}$ Delft University of Technology, The Netherlands

${ }^{4}$ Tilburg University, The Netherlands

5Universidade Federal do Rio Grande do Sul, Brazil

${ }^{6}$ Vrije Universiteit Brussel, Belgium

Corresponding Author:

David Geerts, KU Leuven, Parkstraat 45 Bus 3605, Leuven, 3000, Belgium.

Email: david.geerts@kuleuven.be
} 


\section{Keywords}

assessment, design, $\mathrm{HCl}$, research games, serious games, SGDA

\section{Introduction}

As more and more HCI researchers are using games or game elements at various moments in the design process as a method for eliciting user needs, ideation or designing, there is an increasing need for a structured approach to create such research games. The goal of this article is therefore to provide such a structure, based on the Serious Game Design Assessment (SGDA) Framework (Mitgutsch \& Alvarado, 2012).

While creating and using research games in various projects throughout the years, we recognized this need and started to look for a way to help us create better and more effective research games. We found this support in the SGDA Framework, which we first applied to evaluate two board games that we used in two different projects. Based on this evaluation, we used the same framework as a guide for designing a new research game from the start. This article will follow the same journey by showing the reader which lessons we learned from the first two use cases, and how we applied them in the third use case.

We will first introduce our conceptualization of research games before explaining in depth the SGDA Framework and how this framework has already been used for evaluating and designing serious games in general, and research games in particular. Then, we will provide a detailed analysis of the three research games that we provide as case studies in this article. Finally, we will present our lessons learned as guidance for other HCI researchers that want to use the SGDA Framework for creating research games.

\section{Research Games for Eliciting User Needs and Ideation}

Similar to the way Gee (2007) and Calvillo Gámez, Cairns, and Cox (2009) tried to understand how learning and UX can benefit from the use of games, games may be used to enhance research methods in the field of HCI. The use of narratives is common in games (Mitgutsch \& Alvarado, 2012). Narratives provide interesting opportunities for researchers to give players a glimpse of possible future experiences. As such, games could be used to introduce futuristic elements (such as new products or services) without raising questions about the feasibility and credibility of such elements. Games might create fictional, but natural settings for players to explore, use, and discuss such futuristic elements.

Furthermore, games are often understood as environments in which players feel safe to experiment (Gee, 2007). As most people are familiar with the concept of games from childhood onwards, they know that the context of a game allows them to test new strategies or ideas without repercussions in real life. This may even mean that a gamelike environment stimulates players to express themselves more freely. Therefore, a game might prevent socially desirable responses in a research setting. 
Continuing this line of thought on the social benefits of game-based HCI methods, games may be used to enhance group processes. Several research methods common in HCI require a group setting (e.g., focus groups or workshops). Research on group settings has found that social phenomena such as production blocking, social loafing and fear of evaluation might arise and block the creative process (Furnham \& Yazdanpanahi, 1995; Warr \& O’Neill, 2005). As playful and relaxed atmospheres have been shown to stimulate creativity (Mumford \& Gustafson, 1988), games may be an interesting instrument to improve group settings in research. Games may, in this respect, facilitate a more balanced contribution of all participants, for example by using turn-taking or by letting players participate from the viewpoints of different roles or game characters, similar to the Six Thinking Hats thinking tool (De Bono, 1985). Another social benefit of using games in HCI research may be found in the casual character of a game. A relaxed setting reduces the threshold for participants to contribute and acts as an icebreaker if participants do not know each other.

Literature on game-based research methods, to specifically collect data about (future) users, in HCI is still scarce. In design research, however, and in participatory design in particular, the use of games in the design process has been quite influential since the late 1980s. A common purpose of design games is to support insight-driven negotiations between designers and users, and provide inspiration to generate new ideas (Lucero, Dalsgaard, Halskov, \& Buur, 2016). Design games enhance communication and teamwork in participatory design teams, improve articulation of user requirements and lead to new insights (Muller, 2002). Several genres of design games have been identified, such as concept design games, exchange perspective games, organizational games, scenario-oriented games (Brandt, 2006), and idea generation games (Arrasvuori et al., 2011).

More recently, HCI researchers have started to explore how to employ game elements for data collection. More specifically, researchers use game elements to improve participant engagement in the early phases of the design process to elicit user needs or for ideation. Analogous to the term design games, we will refer to such game-based research methods in HCI as research games in the remainder of this article. Design games and research games share a common goal, namely involving end users for designerly purposes. However, research games are different from design games, in the sense that they are used much earlier in the design process to facilitate better participation when collecting insights (as opposed to communicating insights) by integrating several game elements to this end.

The difference is most apparent in research games that have been used at the beginning of the design process, to understand the users' context and needs. Bernhaupt, Weiss, Obrist, and Tscheligi (2007), for example, used card games to make cultural probes more playful. They added creative cards to traditional cultural probes. Adding this playful element enhanced both participants' involvement and the amount of data collected with cultural probes. Also early in the design process, Slegers, Ruelens, Vissers, and Duysburgh (2015), created a board game for train passengers that was loosely based on game elements from THE GAME OF LIFE, MONOPOLY and THE GAME OF THE GOOSE. During the game, players could ask questions to a mockup of a future train information system. The game provided the researchers with 
additional insights on user needs as well as an early evaluation of their design concept. We will discuss this game and how we evaluated it in more detail later in this paper.

Other examples of research games, albeit a little later in the design process, are ideation games, getting closer in nature to what is usually seen as design games. The goal of this type of research games is to generate new ideas, involving one single user group to generate new ideas without collaboration with a designer or design team, as design games typically do. Huyghe, Wouters, Geerts, and Vande Moere (2014) used elements from the Inspiration Card Workshop (Halskov \& Dalsgård, 2006) as well as traditional board games to create LOCALUDO, a game aimed at involving families to generate ideas for interactive sensor and display interventions in a residential urban context. Kultima, Niemelä, Paavilainen, and Saarenpää (2008) described a set of research games based on well-known game elements, to involve game designers. This game set was designed to structure the ideation phase for generating new games and used decks of cards (e.g., based on the game UNO), a game board, cooperative play and solo play, score tokens, and competition. Blythe, Steane, Roe, and Oliver (2015) created a research game incorporating familiar game elements like a board, tokens, quotation cards, technology dice, and earning bonus points. Players, all pensioners aged eighty or older, generated design concepts for positive aging, based on age-associated predicaments and positive qualities of aging. Finally, Huyghe, Nouwen, and Vanattenhoven (2016) made use of a board game to engage hospital staff in defining new ways for using wearable technology to support logistical processes. The board game was based on THE GAME OF THE GOOSE and used technology cards, based on the Lillidot method (De Roeck, Slegers, Stappers, \& Standaert, 2011), to abstract wearable technology. Furthermore, it employed game elements to support discussions among the players in order to understand the trade-offs they make. This last game is also one of the case studies we will discuss in more detail in this paper.

\section{Evaluating and Informing the Design of Research Games}

The idea of using game elements in HCI research may result in new and innovative ways to involve end-users in the design process. However, creating a good game for entertainment purposes is not easy in itself, let alone if a game should support research purposes too. Most HCI researchers have not received training in game design, and may find it challenging to create original and useful research games. The literature on research games discussed above shows that borrowing game elements from wellknown, and rather simple games might instill interesting new research approaches. However, we believe that the potential of research games can only be fully realized once we go beyond the use of basic, existing game principles. To further the use of research games in HCI, researchers should approach each new research game as a novel, multi-purpose game that requires a specific approach. Research games should be entertaining for participants on the one hand, and yield valuable insights for researchers in the early phases of the design process on the other hand.

In support of the development of future research games, we propose the use of the Serious Game Design Assessment (SGDA) Framework, presented by Mitgutsch and 
Alvarado (2012) as an "analytical framework for serious game analysis" (p. 122). In this section, we will present the SGDA Framework, and show how it has been applied in the past for evaluating and designing various serious games.

\section{The Serious Games Design Assessment (SGDA) Framework}

The SGDA Framework (see Figure 1) emerged from a research project at MIT, which explored the impact of serious games that seek to accomplish social change (Mitgutsch $\&$ Alvarado, 2012). The goal of the framework is to structure the assessment of serious games, and enable an analysis of "the formal conceptual design of these games in relation to their explicit and implicit purposes." (Mitgutsch \& Alvarado, 2012, p. 121). As Mitgutsch and Alvarado (2012) emphasized, the SGDA Framework was not intended as a measurement instrument in itself, but as a tool to guide assessment.

The framework was developed because the researchers observed a lack of tools that actually examine the relationship between the quality of the design of serious games and their purpose to make an impact on players (see also Arnab \& Clarke, 2017), who make similar observations in this regard). Mitgutsch and Alvarado (2012) saw this examination as an important first step in the impact assessment of serious games.

When applying the SGDA Framework to evaluate serious games, Mitgutsch and Alvarado (2012) essentially followed a two-step approach. First, they decomposed the game into its constituent components specified by the framework:

1. Purpose: Aim of the game \& intended impact, e.g. making people familiar with a particular technology and capturing their attitude towards it

2. Content \& information: Information, facts $\&$ data visible to the player, e.g. statistics on players' progression in the game and educational content

3. Mechanics: Actions for interacting with the game, governed by rules, e.g. answering a question correctly results in a reward

4. Fiction \& Narrative: Fictional context such as plot and characters - e.g. a player acting as a character in the game that needs to complete a mission

5. Aesthetics \& Graphics: Sensory representation of the game, e.g., a colorful or rather a formal look and feel in the game

6. Framing: How well a game addresses the target group and their level of play literacy, e.g. some people may be more experienced with a given genre or form of game-play

Secondly, following the first analytical step, it is established whether the different design elements are consistent with the overall purpose of the serious game ('coherence') and together form a united whole ('cohesiveness'). Indeed, at the core of the SGDA Framework lies the idea that "the explicit intention and the purpose of the game need to be considered throughout the components of their design" (Mitgutsch \& Alvarado, 2012, p. 124). Incoherence and lack of cohesion in the design will hinder accomplishing the game's purpose and realizing the intended impact. As such, this second step is the most critical from the perspective of the SGDA Framework. 


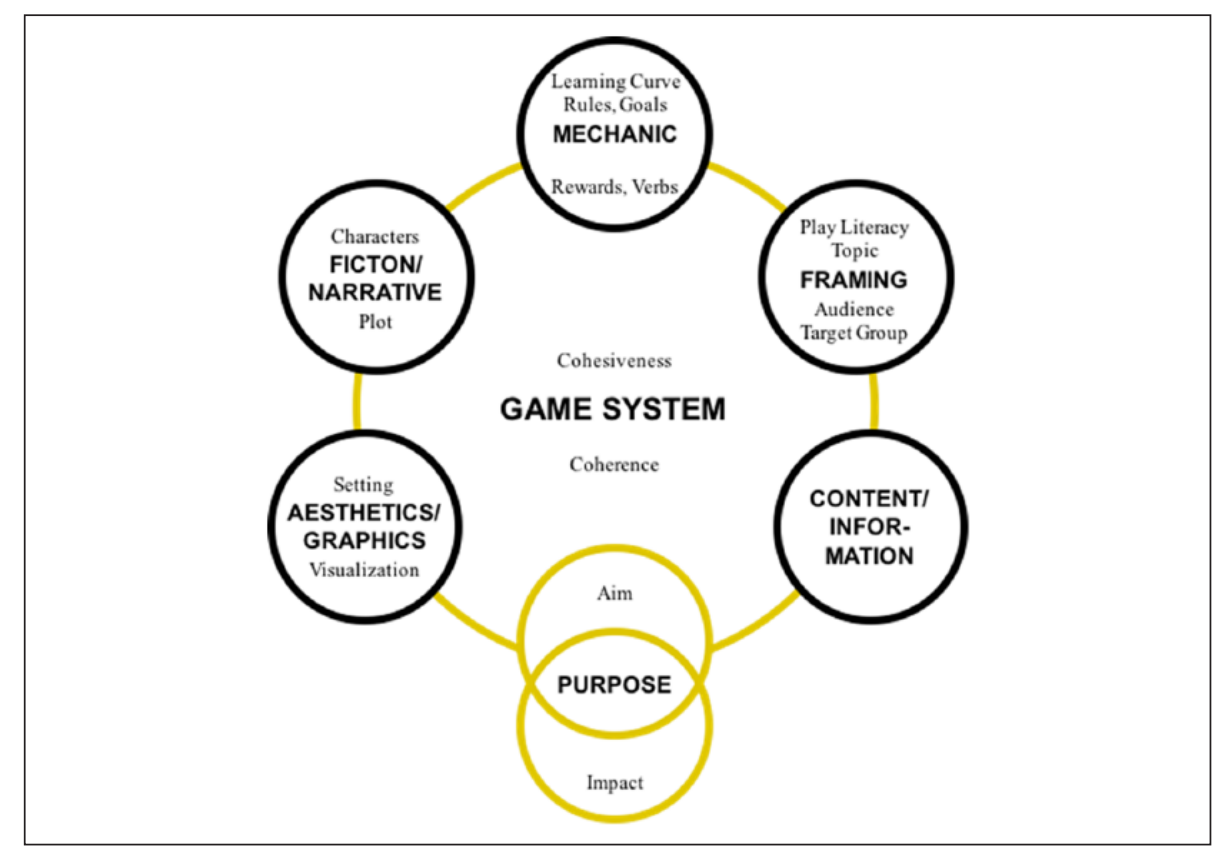

Figure I. Serious game design assessment framework (Mitgutsch \& Alvarado, 20I2).

\section{Applications of the SGDA Framework for Design and Prototyping}

While some authors have used the SGDA Framework to systematically describe, review or evaluate games (e.g. Bleumers, 2013; Sernani, Dalpiaz, Dragoni, \& Brinkkemper, 2015; Wolf \& Lenz, 2014), its application has been further extended. Already in the original article from 2012, it was suggested that the SGDA Framework could be used for the design and prototyping of serious games as well. Since then, several authors have applied the framework for those purposes (Cosma et al., 2015; Mitgutsch, Schirra, \& Verrilli, 2013; Oh et al., 2013; Ross, Fitzgerald, \& Rhodes, 2014).

Mitgutsch et al. (2013) applied the SGDA Framework to inform the design process of a serious game called MOVERS AND SHAKERS. The two-player tablet game seeks to make young workers aware of conflicts of interest and communication challenges that can occur in the workplace and to foster communication in the game with their fellow players. Unfortunately, the work-in-progress article does not yet detail how the SGDA Framework was integrated in the design process. In a sense, the game prototype they describe can be seen as a research game, albeit not in the domain of HCI. The prototype is part of design research on transformational learning and is described by the authors as "a research tool to explore how social design can influence serious game experiences” (Mitgutsch et al., 2013, p. 715).

Ross et al. (2014) described the development of a serious game, SPACE TUG SKIRMISH. This educational card game was created to quickly introduce researchers 


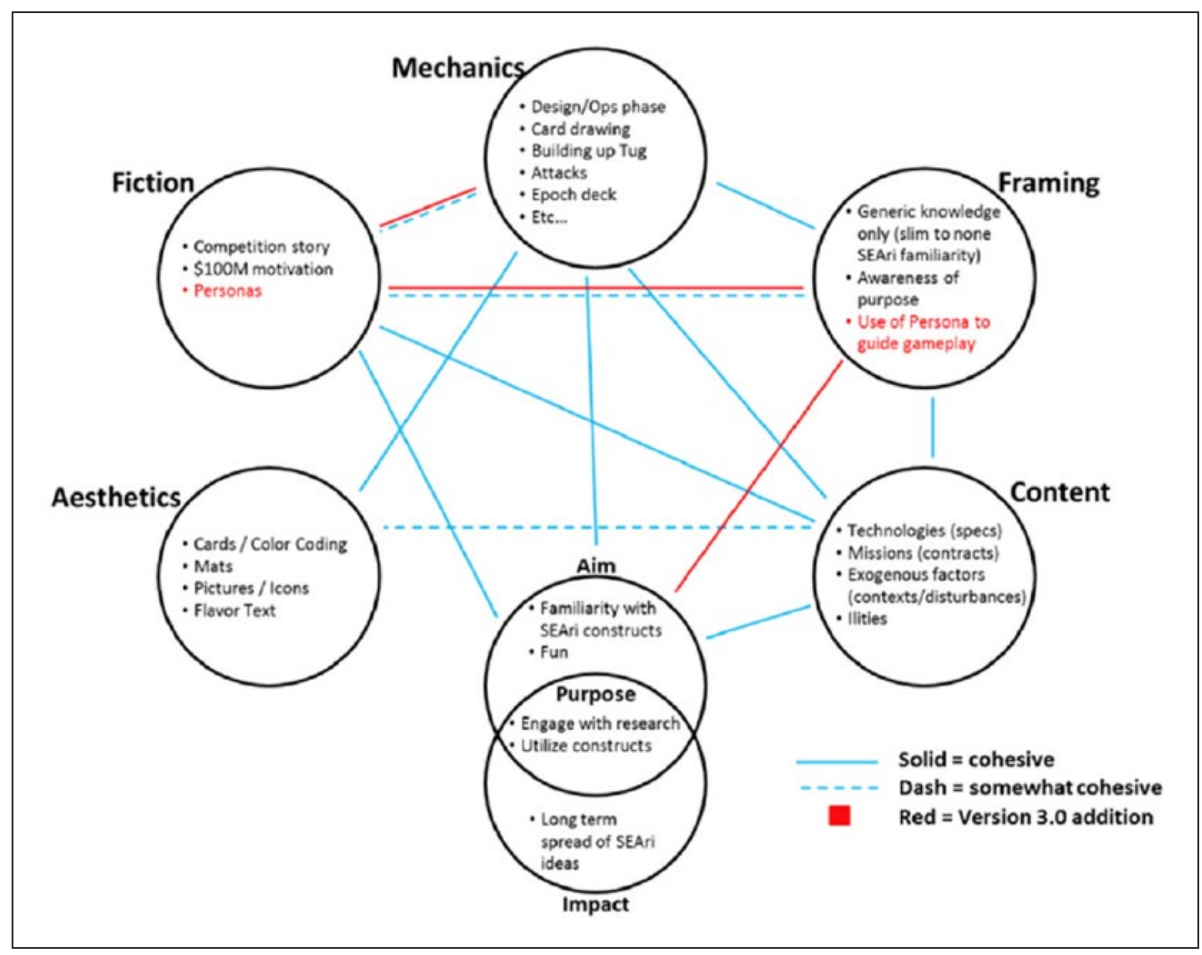

Figure 2. A breakdown of SPACE TUG SKIRMISH with the serious games design assessment framework (Ross, Fitzgerald, \& Rhodes, 20I4).

who are new to the team - working on the MIT Systems Engineering Advancement Initiative - to their core methods and concepts. Additionally, it could demonstrate the contributions of the research conducted throughout the initiative to people who do not have a technical background. The authors used the SGDA Framework to analyze the game, and also visualize how the third and final version of the game marks an improvement in terms of cohesion among the different game components (see Figure 2). While it is not entirely clear whether the SGDA Framework was applied only post hoc, this visualization does show how the framework can be used during iterative design. It is a means to systematically represent different versions of the game, and to illustrate how design choices influence cohesion and coherence within the game system.

Similarly, Schmidt, Scheja, Lam, and Masuch (2015) also used the SGDA Framework to guide and document the design process of a serious game. In this case, student teams first developed a game-based prototype intended to tackle performance anxiety, which was then tested with pupils in a second phase. Schmidt et al. (2015) noted that the framework served as a useful instrument to keep the focus on design goals, especially in the context of dynamic design teams where new members need to be brought up to speed quickly. 
Finally, Cosma et al. (2015) applied the SGDA Framework to guide the co-design process of a serious game; thereby acknowledging that effective serious game design requires different forms of expertise. PROCEE, a game intended to inform AfricanCaribbean men about prostate cancer risks, symptoms and testing, is the result of a collaboration between design and entertainment experts, domain and behavior change experts and the targeted community. The authors described how different stakeholders worked on different SGDA components. One may expect that, because of this approach, incoherence may be introduced through the presence of different stakeholders' perspectives (Arnab \& Clarke, 2017). Unfortunately, the authors do not discuss this further.

\section{Applying the SGDA Framework to Research Games}

The SGDA Framework has been specifically developed with serious games in mind. The concept of research games that we introduce in this article can be seen as a specific genre of serious games. Similar to a serious game, a research game fulfills a dual purpose: (1) it creates an enjoyable experience for research participants in HCI studies, and (2) it has a purpose beyond the self-contained aims of the game itself, namely HCI research goals. Research games are different from most other serious games because the game's serious purpose usually is not to impact the players' lives beyond the playtime of the game. Instead, research games benefit the researchers' need to collect valuable insights to inform the design process. Even though research games envision different long-term beneficiaries (researchers instead of players), the purpose still is one that is often pursued in serious games: researchers use a research game to learn from end-users, to gain a better understanding of their end-users, and to find ways to design meaningful solutions for them.

Considering the dual purpose of research games, we believe that the SGDA Framework can be a valuable tool when creating research games. It can be used as an assessment tool as well as a guidance tool during the design process of research games. To illustrate the applicability of the framework for research games, we assessed two of our own research games, and designed a third game based on the SGDA Framework. In the following section, we describe these games according to the core elements of the SGDA Framework.

\section{Three Case Studies: The SGDA Framework Applied}

This section describes in detail three research games we developed, based on the components of the SGDA Framework. For each game, we apply the two-step approach of the framework by first decomposing the game into its constituent components, before assessing the coherence and cohesiveness of the game. As mentioned earlier, for the first two games the SGDA Framework was applied post hoc for evaluating the different elements of the game, while for the third game the framework was used as a tool to guide the design of the game. 


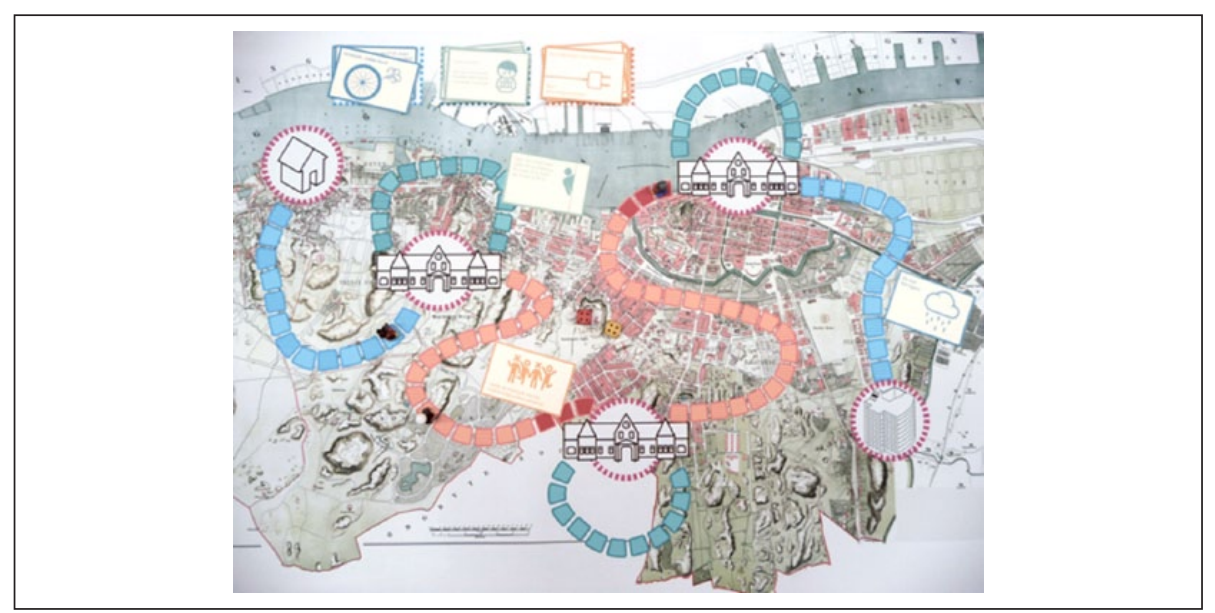

Figure 3. The TIS board game.

\section{Train Information System Board Game}

The first game (Slegers et al., 2015) was part of a research project aiming to develop a proof-of-concept of a new train information system (TIS). Since a core element of the new TIS concerned the proactive presentation of relevant information to individual train passengers, we wanted to understand which questions occupy train passengers' minds during different phases of a train journey. Also, we wanted to confront train passengers with the concept of an all-knowing TIS that could answer any question by giving information that goes beyond existing travel apps. For this purpose, we created a board game (see Figure 3).

The board game was inspired by several well-known games. The track loosely resembled the track of THE GAME OF LIFE; the blank and penalty squares were borrowed from THE GAME OF THE GOOSE; and players could draw event cards, similar to the Chance and Community Chest cards in MONOPOLY. During the game, players could ask questions to a (Wizard-of-Oz operated) mockup of an all-knowing TIS via a tablet. Players played the game in couples, usually 3 couples per game table. Each game was moderated by a researcher, who would also facilitate discussions among the players about the questions they asked the TIS mockup and about the usefulness of the answers they received. The game was played with 30 train passengers (in groups of about six players).

Purpose. The main research aim of the TIS board game was to collect data concerning the types of questions that occupy train passengers' minds. In addition, the game was specifically designed to facilitate future thinking by having users experience a product that doesn't exist yet (the all-knowing TIS).

Besides this research aim, the game also intended to provide the research participants with an enjoyable experience. Most of them did not know each other, and we hoped that a board game would facilitate the group process (e.g., by acting as an 
icebreaker and by offering a safe research environment, making participants feel at ease). The game seems to have reached this anticipated impact, as most of the participants who filled in a short questionnaire afterwards $(n=20)$ indicated that they were pleasantly surprised that the study consisted of playing a game, and that they felt at ease playing it. From the researchers' perspective, the game served its purpose too, as the logging data of the questions players asked the TIS mockup as well as the discussions between the players yielded insights that were not gained during previous observations and interviews.

Content \& information. Most of the game's content and information concerned train information, e.g. the events on the event cards and the answers of TIS mockup. The event cards were added to introduce real-life events that could serve as a specific context for asking questions to the TIS mockup. On these cards, realistic (and often frustrating) train experiences were represented in thought bubbles resembling train passengers' thoughts as well as matching pictorial illustrations.

The answers of the TIS mockup provided textual, fictional, and futuristic content to the game. These were provided on the spot by one of the researchers, who would, in another room, quickly come up with TIS-like answers to the questions the players typed on the tablets. In answering players' questions, the researcher would try to go beyond information available in existing train applications (e.g. by linking unexpected data sources, or by providing highly personalized information). The answers would, for instance, emphasize the proactivity of the TIS by suggesting alternatives or solutions to the players (e.g., "The bike parking where you normally park your bike is very full, you'll be quicker to park your bike at the back of the train station."). By offering such future-oriented answers, we hoped to trigger participants to think more creatively about the opportunities of the futuristic TIS when asking questions in later phases of the game. As a result, several players started to 'test' the TIS by asking more extreme questions (e.g., "I'm not feeling relaxed right now, could you play me some soothing music?"). As such, the content provided by the Wizard-of-Oz researcher on the spot facilitated creative and future thinking on behalf of the players.

No specific information about the players' statistics was provided. However, the position on the board of the pawns (see 'Game mechanics') provided immediate information on the ranking of the players.

Game mechanics. Basing the design of the game on well-known family games was done to create a game that would feel familiar to participants, and to prevent an overly complicated game. Players had to throw a set of dice, move their pawn accordingly, and (if landing on an event square) take an event card and read it out loud. Next, they could ask a question to the TIS. The in-game purpose (or the win condition) was to be the first team to arrive at the last square.

The game also included a reward system: if players decided to ask a question to the TIS mockup, they were allowed to throw the dice and move their pawn again. Asking a question to the TIS mockup was deliberately not a mandatory act, as we aimed for a realistic train journey experience and anticipated that some situations would not 
trigger any questions. However, as it was a main purpose of the game to collect data about questions train passengers would ask if they had an all-knowing TIS at their disposal, we did want to stimulate asking questions.

The events on the event cards acted as playful game obstacles in the game, introducing unpredictable turns of events. The track also contained red penalty squares, introducing additional obstacles as players who would land here had to skip a turn (due to delays).

The board game had just one single difficulty level, as creating a difficult game was not our intention. Moreover, we had players playing in teams of two to facilitate asking questions. This allowed them to discuss what questions to ask and gave us insight in the questions they considered to ask and in the motivations for asking questions.

Fiction \& narrative. The narrative of the board game was based on a typical everyday train journey. Players were told their journey began at home and that they had to travel to an unspecified destination by train. The track on the board represented three main journey phases: leaving home to go to the train station, the train journey itself, and the journey from the arrival station to the final destination. Frequently, incidents would disrupt the train journey posing problems to the players.

We deliberately decided to provide very few details that could form the back story for the narrative (e.g. naming specific train stations was avoided) to allow players to create the narrative of the game themselves, based on their own experiences with train journeys. With these design choices, we aimed to collect a wide variety of data on passengers' questions, not steering participants towards location-specific situations or circumstances.

The TIS mockup was also part of the narrative, as we explained that players could use a futuristic, all-knowing TIS. We told them the TIS, which they could operate via a tablet, was an early mockup developed in the research project. We emphasized the fact that this TIS was all-knowing and that players could ask anything that could help them in reaching their destination.

Aesthetics \& graphics. The background of the board game was a map of an unspecified city (see Figure 3 ) to avoid location-specific knowledge of players to become relevant in the game (see 'Fiction \& Narrative'). Each phase of the train journey (see Fiction \& Narrative) had squares on the track in different colors, matching dedicated event cards (see Figure 4). The lines of the squares, either solid or dashed, indicated whether players could draw an event card. Squares with red lines were penalty squares (see 'Game mechanics'). Abstract building images represented the starting point and destination. The event cards contained a playful, textual description of an event (see 'Content \& Information') and a pictogram-like illustration. For the TIS mockup we used a standard, freely available chat app which was chosen for practical reasons rather than aesthetic ones.

Framing. The target group of the game was rather broad, consisting of people who (occasionally) travel by train. As we used mechanics from well-known family games, 


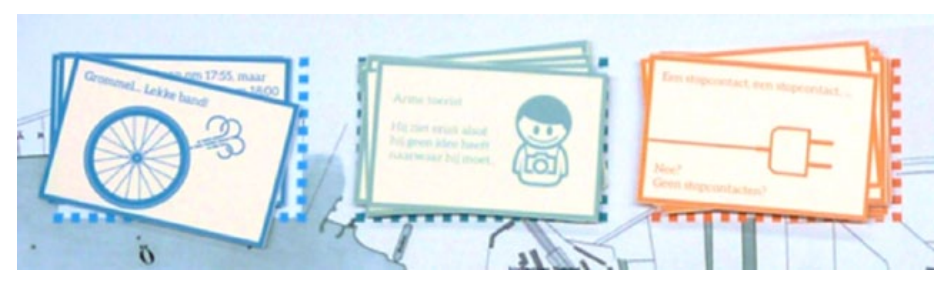

Figure 4. The TIS board game event cards.

play literacy was not much of an issue. Moreover, the survey results showed that the vast majority of the participants $(85 \%)$ enjoyed playing games regularly. The rules were easy to explain and understand, and a moderator was present during the games to clarify any ambiguities. The moderators also explained that the board game was a research tool, and that the game session as such was actually a study. We told participants that we wanted to evaluate an early mockup of the TIS concept and that the board game was designed to facilitate this.

Coherence \& cohesiveness. When analyzing the coherence and cohesiveness between all SGDA elements for the TIS board game (see Figure 5), it became clear that the mechanics and content of the game are strongly coherent with the overall purpose ( $\mathrm{I}$ in Figure 5). The TIS mockup stimulates future-oriented thinking by giving information and recommendations that travelers would not expect from existing train applications. Furthermore, rewarding players for asking questions to an all-knowing system, facilitates researchers to gain insight in the questions participants might have.

The SGDA components fiction/narrative \& aesthetics/graphics also seemed to fit each other well (II in Figure 5), but may also have compromised the game's purpose. By not specifying the exact setting (e.g. by using name of cities), we aimed to encourage players to contribute to the narrative. However, the lack of a personal context, may have made it difficult to think of issues common in everyday travel. As we saw, even some seemingly abstract cues may have evoked an unfamiliar context. E.g., the office building pictogram may have suggested a commute, while some participants only used the train for leisure trips.

Furthermore, the game mechanics are nicely aligned with the narrative of a train journey and the broad group of participants (III in Figure 5). The use of classic board game mechanics in this respect had two benefits. On the one hand, the idea of using a track on a board to represent the narrative of a train journey is well reflected in the game. Furthermore, mechanics such as turn-taking, dice throwing, etc. are game mechanics most people are familiar with. This allows researchers to avoid steep learning curves and only introduces low difficulty levels. This was important, as we did not know beforehand whether participants would be familiar with playing games. 


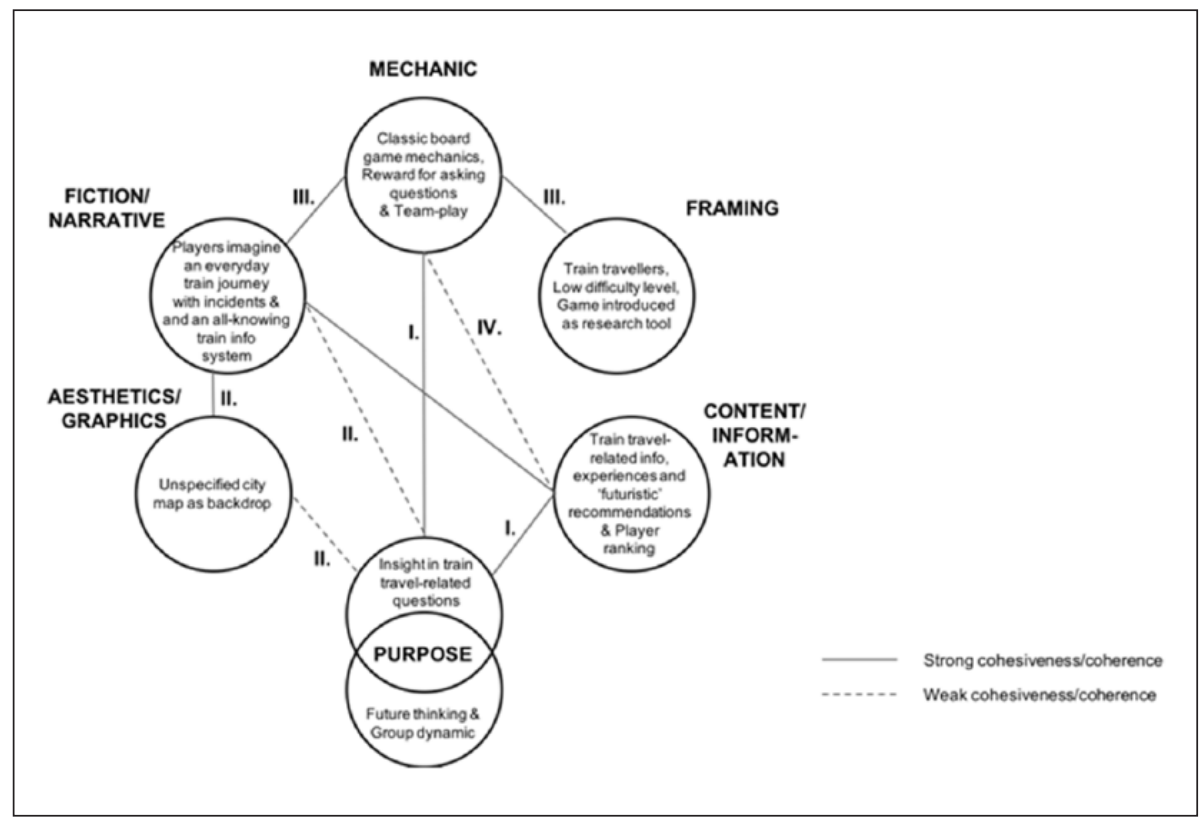

Figure 5. Coherence and cohesion between SGDA elements for the TIS board game.

Finally, the analysis of cohesion and cohesiveness showed some mismatches, mostly related to the game mechanics and content/information (IV in Figure 5). Most importantly, the TIS did not have a clear function in the game mechanics. Indeed, the reward for asking a question was unrelated to the content of the question and the answers the TIS gave did not help to reach the in-game purpose.

\section{Wearables for Hospital Logistics Ideation Game}

The second case study was part of a research project investigating dynamic planning software and the design of wearables to support logistical processes in hospitals (described in Huyghe et al. (2016)). We employed a research game to facilitate hospital staff of patient and goods logistics to think about possible ways of interacting with wearable devices to give feedback on their activities and receive new tasks.

The game (see Figure 6) consists of a board with a track and penalty squares (inspired by GAME OF THE GOOSE), pawns, dice, problem cards and three categories of technology cards (input, 'gnome' and output - see section 'Content and information' below for more information). The game was played in two hospitals, each time with six employees involved in patient or goods logistics (12 in total for the entire case study). One researcher guided the players, while another researcher took notes of the course of the game and the ideas and discussions generated by the participants. 


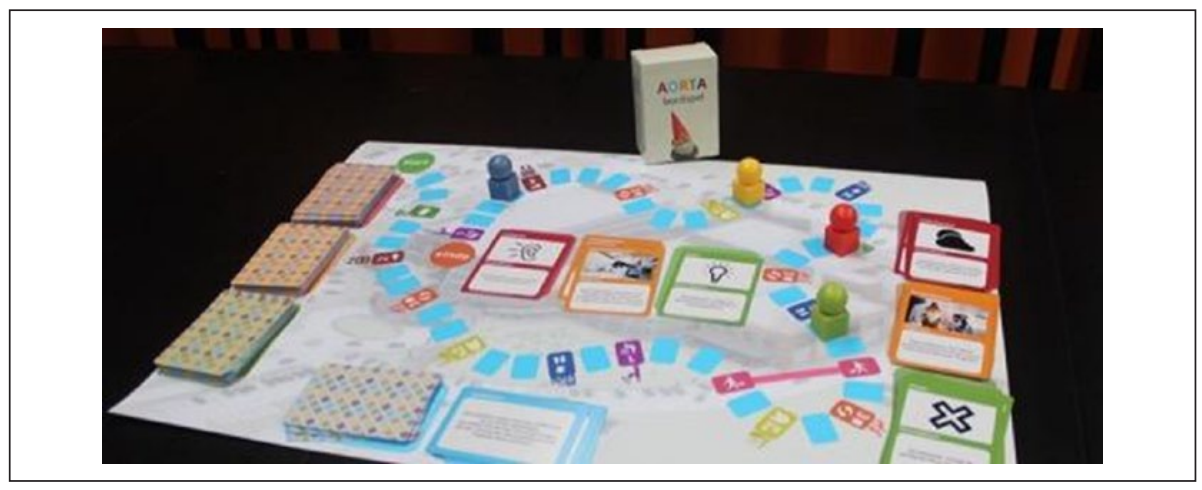

Figure 6. The hospital logistics game board lay-out.

Before playing, one researcher introduced the project, the purpose of the session and the game rules and cards. The moderator ended the game after an hour, when each team of three players had played an equal amount of turns. The winner was the team who had advanced the most. Lastly, the researchers and participants evaluated the board game.

Purpose. The research game served three purposes: 1) involve hospital staff in future thinking about unknown technologies that might impact their work practices, 2) ideate on technology-related (rather than process-related) problem-solving with a fictitious but familiar narrative, and 3) collaborate with end-users to uncover possible interactions with wearables.

This research game aimed to impact both the researchers (i.e. gaining user input on wearable technology), and the players (i.e., providing a relaxed and enjoyable atmosphere to facilitate technology acceptance). Our motivation for the latter is grounded in the fact that the participants were assigned to participate by their superiors on top of their busy schedule and the unfamiliarity of the players with team members from other logistical flows. In session 1, one participant was initially negative about her "having" to participate after her working hours. By the end of the session, however, she collaborated with her team members in a constructive manner. In both sessions, the teams composed of players from different departments found common ground while discussing differences and similarities in their work. Hence, we succeeded in supporting collaboration by providing a fail-safe environment.

Content \& information. We introduced problems that were relevant to the players' work practice (as identified in a prior contextual inquiry study) on individual problem cards, to instill familiarity with the game environment. While playing, players were randomly confronted with typical work-related problems. For instance "when you arrive at the patient's room, this patient is having a warm lunch" (the problem being that the hospital porter lost valuable time to transport other patients, as (s)he cannot 


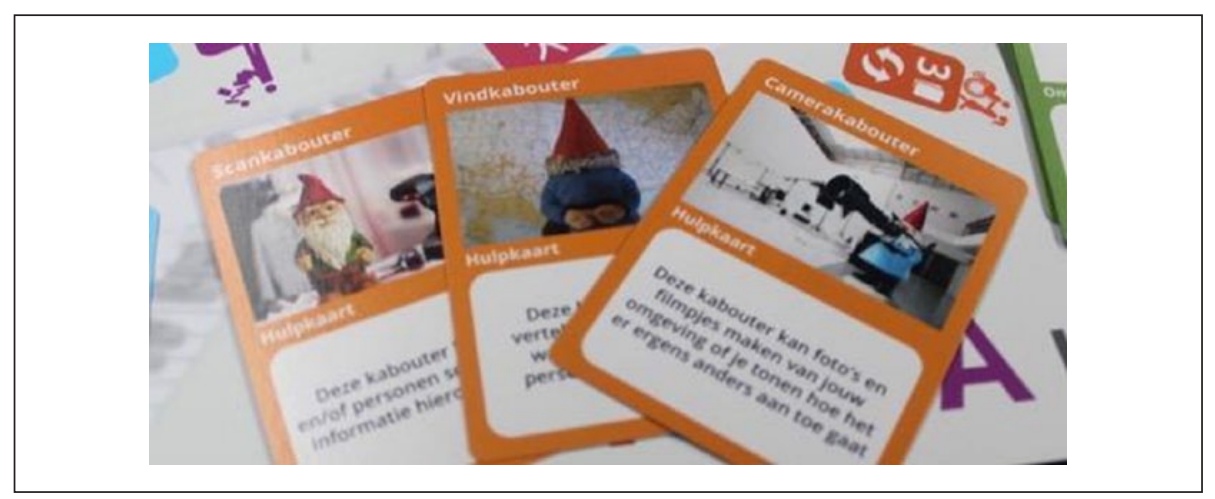

Figure 7. 'Gnome' technology cards.

transport patients when having a warm meal). Overall, the participants agreed on the accurateness and importance of the introduced problems. We believe this stimulated engagement from all participants.

In order to facilitate idea generation, we introduced technology cards to break down the available technologies (see the Inspiration Card method (Halskov \& Dalsgård, 2006)). Inspired by the Lillidots method (De Roeck et al., 2011), these cards used the metaphor of little gnomes that help hospital porters with their tasks (see Figure 7).

Each gnome possesses knowledge or a skill related to wearable devices (e.g., cameras, barcode scanners, calendars), translated in human-like skills (e.g., the camera gnome shows images from different locations in the hospital). Additionally, we provided cards for input and output modalities, representing wearables' functionalities such as touch, gesture, sound, light, text, etc.

Game mechanics. The starting point for game mechanics was THE GAME OF THE GOOSE. For ideation purposes, we made three adaptations to the board and the rules:

1. When the players landed on a problem square, they could draw one problem card (see above) to facilitate on-topic future thinking and generate ideas;

2. The action squares, that advanced or hindered play, were related to the players' work context (e.g., the elevator is busy) to increase familiarity;

3. The players played in two teams to instill out loud discussions within and between the teams, to comprehend the different elements that contributed to the solutions and (un)desirable interactions with wearables.

The gameplay unfolded in different steps. When a player of the first team rolled the dice, the piece was moved accordingly on the track to land on an action or problem square: 
- Action square: the turn was limited to the action on the square, e.g., skip a turn),

- Problem square: the player read one drawn problem card out loud and discussed possible solutions with the team. Each team member contributed equally, as each player received three cards from a different category at the beginning of the game. When the team presented the solution, the other team could suggest an improvement by replacing a technology card with one of their own cards. The researchers moderated the resulting discussion.

The second team's turn started when both teams decided that the proposed change improved the initial solution. In this case the second team could use two dice as a reward. If the proposed change was not an improvement or no improvement was proposed, the second team could use only one dice for their turn. The teams changed turns accordingly.

Whereas the problem cards were presented randomly in the first session, the problem cards were ordered from simple to more complex in the second session. This decision was made in order to allow the players to get acquainted with the game rules before tackling complex problems.

Fiction \& narrative. The game's narrative revolved around future possibilities for the hospital logistic work environment. To achieve clarity, we used problem statements that matched current practices and deconstructed unfamiliar technologies in layman terms on the technology cards (e.g., "the calendar gnome can ask for any information on your colleagues' calendars and make changes"), input cards (e.g., "the gnome asks for attention with a spoken message") and output cards (e.g., "the gnome comes into action by reading emotions"). As the players randomly drew problem cards, the narrative was created by the players while they imagined going about their tasks using novel and unexplored possibilities of wearable technologies.

Aesthetics \& graphics. The hospital environment was conceptualized on the game board by depicting a scale model-like hospital. Furthermore, the different action squares depicted icons of people and tools specific to a hospital environment and were differentiated from one another using different colors. The design of the cards (see Figure 8) was intended to imitate existing card designs, with a color-coded diamond back and a front that resembled 'MAGIC: THE GATHERING' trading cards. These cards consist of a title and image on the top half, and a short description on the bottom half. The images for the gnomes were created using images found online and image editing, while the input and output cards used icons found on the Noun Project (https://thenounproject.com/).

Framing. Since the players participated as professionals, the emphasis was on the goal of the research game. We made sure to explain to the players that the goal was to look for novel ideas, by asking players to assume all existing technologies were removed from the hospital. We emphasized that the game session was not meant to evaluate 


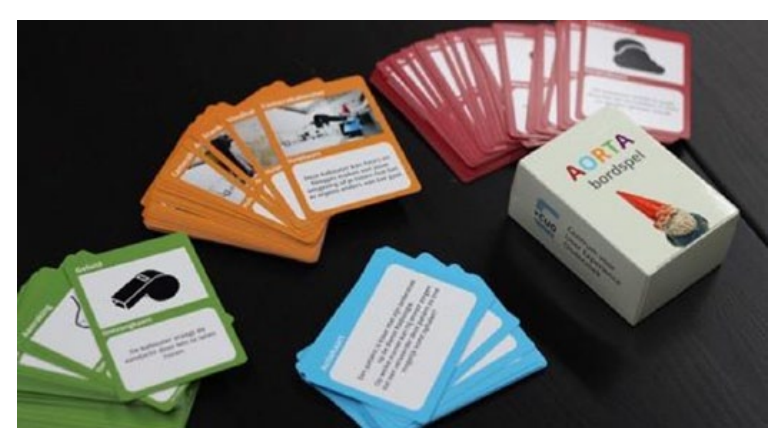

Figure 8. Output (green), gnome (orange), input (red) and problem cards (blue) created for the hospital logistics game.

their current work practices and systems. Instead, we mentioned their input was paramount for future design since they are the experts of their work routines and environment.

The rules of the game proved simple and easy to learn, which minimized the time needed to teach players the game mechanics. More time, however, was needed to properly introduce the different technology cards, as these were not always intuitively clear.

Coherence \& cohesiveness. Most coherence could be identified between the game mechanics, the content and the purpose of the game (see I in Figure 9), as this was carefully considered from the start. The game mechanics encouraged the players to use the information and tools at hand. Also, the game mechanics facilitated collaboration and idea generation between players with different professional backgrounds. The reward mechanic (i.e., double dice roll) served its purpose well, as it led to lively discussions on desirable improvements.

In addition, there is coherence between narrative and content (see II in Figure 9). Framing the content on real-life observations, in the form of problem cards, enabled the players to add to the narrative in a realistic way, true to their own daily experiences and actions.

One of the weaknesses relates to the card design. Instead of considering which card design might be easily understood by our participants (see III in Figure 9), we relied on well-known examples for ourselves (i.e., MAGIC: THE GATHERING). Second, by introducing the technology cards all at once, we may have raised the overall difficulty of the game (see III in Figure 9). Third, as the problem cards were drawn randomly in the first session, the players had to find solutions to difficult problems when they were unfamiliar with the technology cards. When altered in the second session, this difficulty did not occur. 


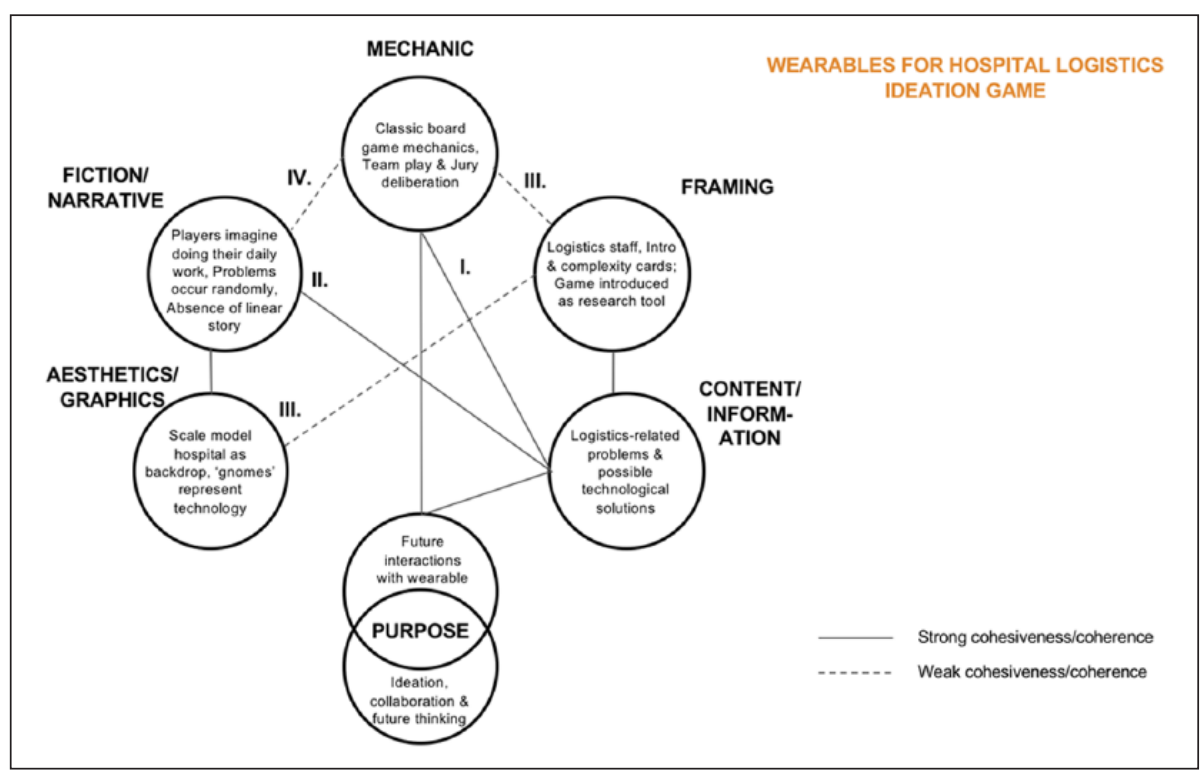

Figure 9. Coherence and cohesion between SGDA elements for the AORTA board game.

Finally, we uncovered a weakness in terms of coherence between the narrative and game mechanics (see IV in Figure 9). The linear path visualized on the board game does not match the randomness of drawing problem cards (in accordance with the random occurrence of logistical issues throughout a work day), which questions the usefulness of the board game in the context of hospital logistics. Instead, we might consider other ways of visualizing progress in the game (e.g., by using tokens), in line with the play literacy of the players.

\section{The Future of Watching Television Board Game}

Our third and final case study was carried out in the context of a project with the goal of generating ideas for the future of watching television and video within a time-frame of five years. For this purpose, we decided to develop a research game that would provide an accessible setting for the participants to conceive and depict futuristic situations (products or services that do not exist yet). Furthermore, we envisioned the game to be an open, enjoyable and casual research activity for all age groups, matching the target audience of watching TV and video.

In contrast with the previously discussed board games, we applied the SGDA Framework during the development of the research game to guide its design. In addition, before using the board game in the workshops, we tested a rudimentary first version of the game as well as a more sophisticated iteration during two try-out sessions with experienced researchers. 


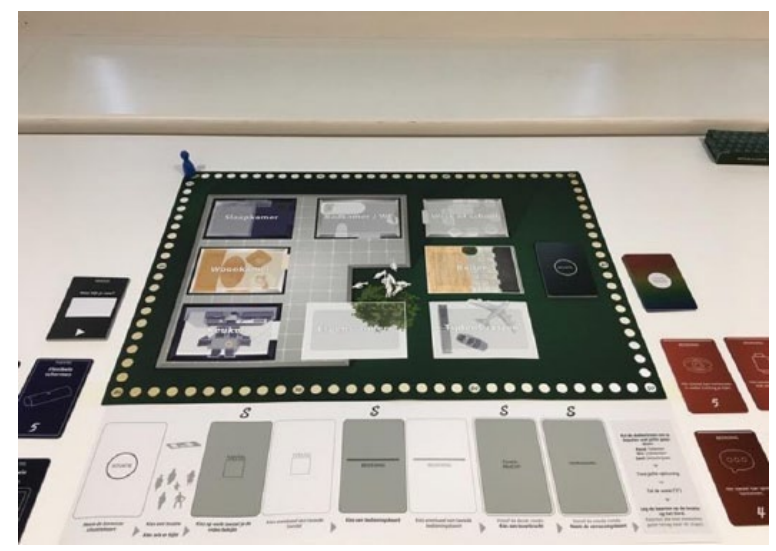

Figure 10. The Future of Watching Television board game.

The board game (see Figure 10) was played in two workshops, one in the Netherlands with 4 Dutch families, and one in Belgium with 5 Flemish families (20 people in total).

Purpose. The game was intended to provide the researchers with ideas for the future of watching television and video in the home. More specifically, we wanted to: 1) Facilitate future thinking and enable end-users to design and develop a scenario of technology usage in 5 years' time; 2) Provide the research participants with an enjoyable experience; 3) Provide structure to a research activity and stimulate social interaction in the group.

The game was indeed successful in reaching the goal of providing ideas and knowledge to the researchers. Participants were able to come up with a wide variety of future scenarios connecting and questioning current practices and future technologies (e.g. could one be immersed in VR-content in a public space?). Regarding the impact on the players, the atmosphere during the workshops was perceived as positive, relaxed and playful by the researchers, which was confirmed by the players in a questionnaire afterwards.

Content \& information. As we wanted the players to imagine and design for the future of watching television and video, we introduced several technologies that are currently predicted to play a role in this future context, sourced from existing literature. Each turn required the participants to make a combination of the following content elements which were depicted on playing cards.

- A randomly picked situation: e.g. a moment of relaxation in the evening, staying up to date with the news during the day, ... 


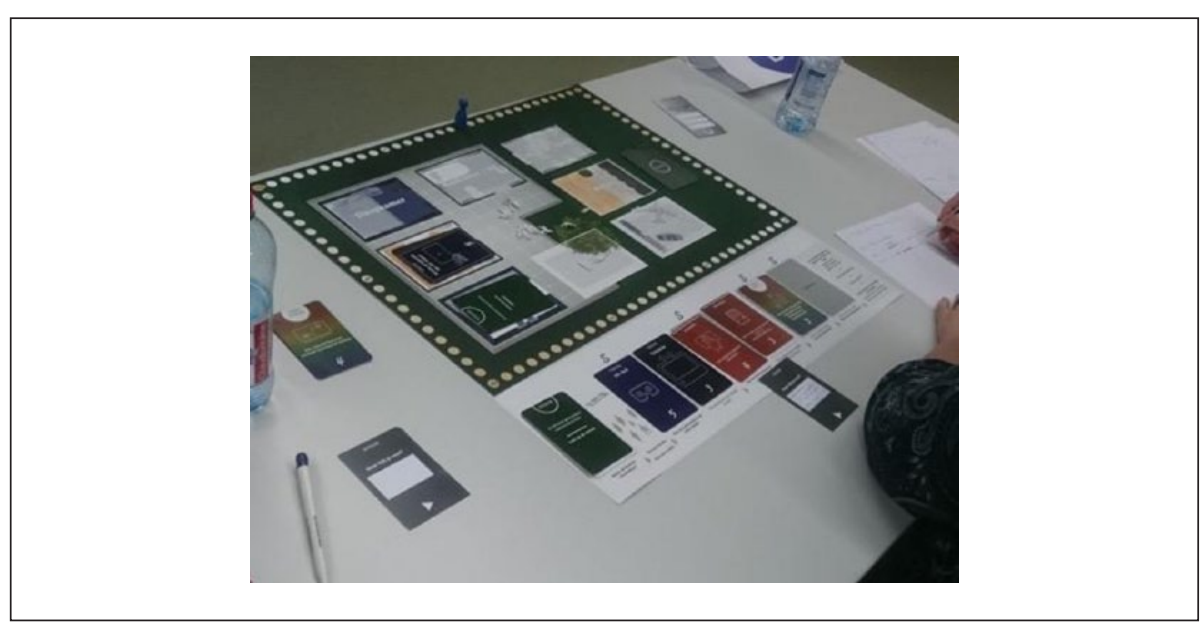

Figure II. The main board and auxiliary board as used during the workshop.

- An output device: the screen on which the content was watched, e.g. TV, VR-goggles, flexible screens, ...

- An input device: what type of interaction controlled the playback, e.g. speech, remote control, ...

- A magic power: an extra interaction feature, e.g. emotion recognition, interactive narratives, ...

The participants needed to place these elements on a game board with locations in, around and outside the house. The players also used miniature figures to indicate who was watching. A final content element was a set of surprise cards that were used during the moment of presentation (see game mechanics), indicating e.g. a change in available time or noise from outside.

Game mechanics. The game mechanics that we employed are based on those that can be found in well-known (party-) games. Inspirations were PICTIONARY, ${ }^{1}$ CLUEDO $^{2}$ and PARTY \& $\mathrm{CO}^{3}$

The game was played in rounds. In each round, a combination of different types of cards was made. To guide the players to compose a full situation in each round, we developed an auxiliary board with the outline of each card and other elements that would be used (see Figure 11). On that board, the elements were placed in a specific order to be followed by the participants.

Each round consisted of three phases. The first phase involved making a specific combination of cards. First, each family took the top card from their (shuffled) stack of situation cards. Then they chose a location on the board where the scenario would take place. Next, they chose the video content and defined who of the family members (or other people) were watching it. The participants then picked one or two output 
(device) cards, and one or two input (control) cards. After a first introductory round where we guided the families step by step, two normal rounds followed with only these cards. As of the third round, a magic power card was added as a mandatory element to compose the scenarios.

In the second phase of each round, the participants threw a dice with three different colors to determine how they would present their scenario to the other participants. Each color represented a specific type of presentation: drawing, acting out, or explaining verbally without using the name of the output device (a taboo word). They then had some time to discuss within their family how they would implement the chosen elements in a scenario and present it to the other participants.

During the third and final phase of each round, one or more members of the families presented their scenario to all participants in the workshop. The presentation ended with some questions and discussion by the facilitating researchers and the observing participants in the audience. As of the fourth round, the families drew a surprise card from the hand of the researchers after which they had to adapt their story and include this new element. Finally, each family had to fill in an audience award card to rank the three best presentations of the other families. At the end of each round, their scores were counted and the used cards were placed on the location they had chosen on the board.

Each output, input, magic power, and surprise card had a certain amount of points attached. We used a counting system that encouraged the use of less standard scenarios including more futuristic elements (e.g. a smartphone gets the team three points, a flexible screen five). As the participants could pick two input and two output cards, but this was not compulsory, only one (the highest scoring) card was counted. We did this to stimulate interesting combinations with existing technology (e.g. pairing a smartwatch with the TV) without penalizing them for it.

Not only could the families earn points by playing highly ranked cards and win the game if they received the highest score, the points from the audience award cards were added up separately and the highest scoring family in this ranking received the audience award. This separate system was introduced to encourage the participants to pay attention while the other families were presenting, as well as to stimulate them to give a good presentation.

Reflecting on the game mechanics, the game did indeed challenge the participants in coming up with creative ideas. Winning the general prize, however, was not much of a strategic challenge, the strategy was to just pick the high scoring cards (which was desirable for the research purpose). The participants were however not primarily motivated by the scoreboard, as they considered their performance during the presentation phase as more important. This suggests that social dynamics are an essential motivation for the participants' game play, and also contributed to the research purpose by providing an explanation for the chosen scenarios.

Fiction \& narrative. There was no real narrative arc in the game, other than the provided situations as context for creating the short individual stories told, enacted, or drawn by the participants. The element of fiction was predominantly provided by the futuristic nature of the scenarios supported by the technologies introduced on the cards. In the 
presentation phase, the participants envisioned and participated themselves in the future scenarios. In this sense, the fiction depended largely on participants ability to act, draw or tell convincingly.

Aesthetics \& graphics. As the locations were a central element of the game, and the first choice each set of participants needed to make after receiving a situation card, we designed the aesthetics and graphics of the board referring to a home environment, as this is where most television and video watching behavior takes place. We also added some locations outside of the house, as mobile devices allow for more flexibility where to watch video. This focus on locations made us choose for the look and feel of the game CLUEDO, which is based on the layout of a house.

The main focus for the aesthetics and graphics of the rest of the material was to make it look well designed, enjoyable and understandable for all age groups. Furthermore, the colors of the cards supported the easy recognition of the various elements (e.g. input cards were orange, magic power cards had a rainbow pattern). Icons used were designed to be simple and clear for everyone. More abstract technologies (e.g. the magic powers) required more abstract icons. We avoided using too much futuristic imagery to still keep it relatable to participants, and focus on the not so distant future (5 years from now).

Framing. As we invited a broad range of participants to the workshops (including children), we designed the board game as a family party game, referencing familiar games from childhood, and making it suitable for all ages. In a questionnaire completed after the workshops, most participants indicated that they liked to play board games in general $($ median $=7 / 10)$. From the initial contact with the participants we were open about the research intentions of the project, explaining that the goal was to gather insights from end users about future technologies in their own context.

The participants were introduced to the technologies by sensitizing videos before the start of the workshop. This increased their literacy in the technologies. Despite this and taking extra care to let all participants speak their mind, creativeness and literacy of the technologies was indicated as a hurdle by some of the older participants. Finally, the described situations on the situation cards were also aimed at matching a wide range of families.

Coherence \& cohesiveness. Already during the development of the game, we analyzed and improved several issues with coherence and cohesion. Every element (mechanics, aesthetics, etc.) was designed to serve the purposes of the game, as intended by the SGDA Framework. However, after playing the game and evaluating it we still detected some hurdles in the gameplay resulting in a few issues regarding coherence and cohesion.

Coherence between game mechanics and purpose (see I in Figure 12.) was strong because of the counting system that stimulated creating less standard scenarios, but also by the addition of surprise cards. These were added as a means to stimulate the participants to move the constructed narratives in new directions. Coherence was also created through the presentation of the scenarios. This was an important moment 


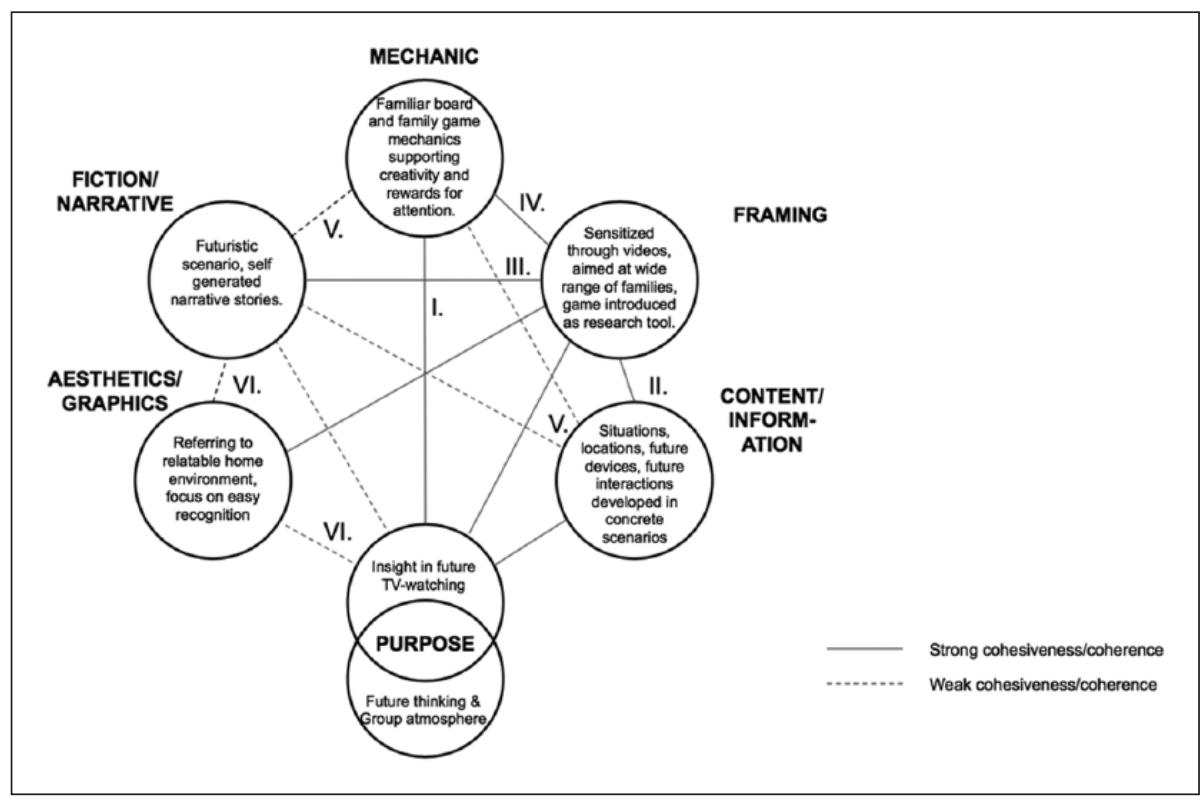

Figure I 2. Coherence and cohesion between SGDA elements for the FUTURE OF WATCHING TELEVISION board game.

during each round to stimulate the participants to clarify their solution. It was also conceived as a fun moment for the participants, as it was based on a chance element through the throwing of a dice. There was, however, also a mismatch between the game mechanics and the purpose. Participants indicated that after a while their creativity was exhausted. In this way, the game mechanics might also have limited some solutions.

We ensured strong coherence between content and framing (see II in Figure 12) by showing the participants videos about the new technologies before the workshop. However, some situations did not match the players' own experiences, e.g. people who work from home would not recognize the work situation. This might have resulted in more hypothetical scenarios.

As our participants were regular television and video viewers, there was a strong coherence between framing and fiction/narrative (see III in Figure 12). Some older participants, however, indicated that their age might have influenced their views on technology, which could have resulted in different scenarios.

As discussed earlier, most participants enjoyed board games in general, and also like the game approach during the workshop, suggesting a strong coherence between game mechanics and framing (see IV in Figure 12). One of the participants however described the game as school-like, and did not appreciate the presentation to a larger group. 
A mismatch we only discovered when playing the game, was the over-representation of the smartwatch. This device could be used as input as well as output, but this meant that the smartwatch came up more often than other input or output devices. The game mechanics allowed for (and even encouraged) the repeated use of this specific element. This over-use of smartwatches can be seen as weak coherence in the triad: Content - Fiction - Mechanics (see V in Figure 12).

Finally, aesthetics and graphics did not entirely match the fiction and narrative as well as the purpose (see VI in Figure 12). The fiction was the future, but the graphics did not represent this (e.g. in the details of the house). We therefore also mark this triad as a weak cohesion.

\section{Benefits and Limitations of Applying the SGDA Framework}

In this final section of our article we highlight the benefits and limitations of applying the SGDA Framework to research games, based on our experience with the three use cases where we used the SGDA Framework first to evaluate and then to develop a research game. Along with the benefits and limitations, we will also offer some recommendations for other researchers that want to use the SGDA Framework for this purpose.

\section{Benefits}

When creating the first two research games, we mainly focused on the research purpose, and less on making it a valuable and enjoyable experience for our players. While we did think about increasing their participation and creating a safe and relaxed environment, we did not consider in-game goals as much, which are very important for keeping players engaged and motivated. In the third case study, we focused more on aligning game mechanics with framing, so the game would be both challenging and enjoyable for the players.

In the second case study, we introduced a rather simplistic gameplay to our participants. Considering the complexity of the introduced technology, we decided to simplify game play and avoid a steep learning curve. This is in line with the need to consider participants' play literacy, but led to a stronger mismatch between game mechanics and purpose. Instead of removing useful game mechanics to address their play literacy, a proper framing of the general gameplay mechanics, clear and informative graphics on the game board and cards, and gradually building up from a simple game to a complex one during gameplay could have alleviated those concerns. This was what we did in the third use case, which despite the more complex game mechanics was still well understood by the participants.

In the first case study, we struggled with deciding how a team could win the game, what would be the ultimate in-game goal for the players. We settled for reaching the destination as quickly as possible. This did not completely match the research project's purposes, as the TIS we were designing not only aimed for travel efficiency, but for 
optimizing comfort as well. Additionally, we failed to give the answers of the TIS mockup to the players' questions an integrated role in the game. We did come up with a reward system for asking a question (players were allowed to throw the dice once more when they decided to ask a question), but we didn't succeed in giving the TIS content a proper role in the game's narrative. A more holistic view on all game elements could have helped us to find a more elegant way to make sure that the answers of the TIS mockup would actually help players to achieve their goal in the game. Similarly, in the second case study, there was no decision-making by players that influenced the game itself, apart from solving the problems they were presented with. The only way to move ahead was to improve ideas of the other team, which was an intentional way of encouraging participants to discuss the proposed solutions to problems, but as game mechanic was not linked to an in-game goal for the participants. In the third case study, we made sure that rewards were not only linked to our own purpose, but also fit the in-game goal for participants (e.g. by giving a good presentation, they would receive points that would help them win the audience prize).

As most HCI researchers that would like to create a research game are not experts in game design, a strategy that may help researchers is to borrow elements from existing games, like we did in all three case studies. In addition to help with choosing the right game mechanics, this can also help with framing and aesthetics. Using game mechanics from well-known games lowers the required play literacy and will make a research game easy to learn and play, but even game elements from less well-known games may further improve or add to the game experience of the players. When borrowing design elements from various existing games however, one should make sure to safeguard the cohesiveness of the different game aspects, especially making sure that the game elements support the narrative and purpose of the research game. Using the concept of a trump card can be borrowed from trick-taking games, but it can be made more useful by explaining why certain cards are better in your game narrative, and making sure that the use of these cards by players benefits the research purpose of the game.

In sum, we recommend using the SGDA Framework during the development of a research game. This way its creators can take into account the different design components in a holistic way, reflect thoroughly how they may function together to support the overall purpose of the game, make informed design decisions leading to enhanced cohesion, and consider both short-term impact, including enjoyment, as well as potential long-term impact on participants (as promoted by participatory design research). Furthermore, borrowing game mechanics and other aspects from existing games can help HCI researchers to choose the right elements for each of the components.

\section{Limitations}

As we used the SGDA Framework in our third use case both during development as well as afterwards to assess the research game, this helped us to see some of its limitations. As discussed earlier in this article, several mismatches in the third case study were only discovered during the first time the game was played with real participants. 
Running out of creative solutions after a while or the over-representation of a specific device were not detected by using the SGDA Framework, despite taking all components into account. While these could be attributed to oversight by the designers of the game, other mismatches were only apparent because of the specific profile or preferences of the participants, such as finding the presentations too much school-like, or having participants that don't recognize certain relatively common situations. Either way, this shows that the SGDA Framework in itself is not a guarantee that the research game will be well designed.

Our suggestion to overcome these limitations, is to involve the participants more closely in the design and evaluation of the research games, as is good practice in human-centered design. While we did playtest the research games in each case study, we did this with fellow researchers, which were not part of the target group. By involving participants with the right profile for playtesting, an extra cost and time would be added to developing the game, but the actual workshops where the research games are used could yield even better results.

Similarly, when assessing the impact of the research game, a more detailed survey with the participants could be conducted, in addition to using the SGDA Framework as impact assessment. This way, it is possible to establish better whether the intended impact was actually realized and would allow to identify aspects that a researcher may not observe, such as issues with game difficulty or perception of the group dynamic by the participants themselves. Our survey among participants was merely used to understand how participants experienced playing a game as research activity, but did not address more detailed issues or, if relevant, the more longer-term impact of the game on the participants.

Finally, while the SGDA Framework offers a valuable design guide, it is still quite a challenge to create an engaging and successful research game. It is especially challenging to design for the dual purpose of bringing participants in the right mindset and creating an enjoyable experience for them, while at the same time remaining useful for researchers as a research tool. What may help in this respect is to build upon the output of more common research methods in human-centered design. In the TIS board game, for instance, the event cards were based on ideation exercises, in the wearable ideation game for hospital settings, the problem cards reflected real user problems that were uncovered during a contextual inquiry study, and in the TV board game locations and situations were based on a diary study with the participants before a first research activity. As such, in addition to the SGDA Framework that provides a framework for designing a research game, the results of previous user studies can be used to inspire the content of a research game. Personas, for instance, may be used as game characters, user scenarios (both current and future scenarios) could form the starting point for the game's narrative, and the context of use may form a good setting for a research game.

To conclude, if researchers rely solely on their own assessment using the SGDA Framework, they risk missing out on important information that could improve the design of a research game or help establish its impact. Similar to expert reviews and user testing in human-centered design processes, we recommend that creating a 
research game includes both expert assessment (using the SGDA Framework) and iterative play testing. In addition, we recommend to use input from other research activities to help define the content (or even other aspects such as aesthetics \& graphics) in the research game.

\section{Further Work}

In this article, we focus on examining the usefulness of the SGDA Framework as a way to assess and design research games, by analyzing the game components of three use cases regarding cohesion and cohesiveness and reflecting on how the framework helped us to develop research games. We did not factor in the effectiveness of the research games, for example by investigating the link between the degree of coherence between the different design components and the degree to which they met the research goals.

In future work, a more quantitative approach would allow us to take a closer look at the outcome of research games (e.g. how many ideas were generated, what was the quality of the ideas, are there any (lasting) effects on the participants, etc.). This approach would however need a more structured approach (e.g. by organizing a workshop with and without using a board game) in order to provide reliable and comparable results, whereas the current paper presents a rich account of the assessment and design of three very different research games.

\section{Acknowledgments}

We would like to thank all participants that took part in the different workshops with our board games.

\section{Declaration of Conflicting Interests}

The authors declared no potential conflicts of interest with respect to the research, authorship, and/or publication of this article.

\section{Funding}

The authors disclosed receipt of the following financial support for the research, authorship, and/or publication of this article: The work presented in this article was part of publicly funded research projects TraPIST and AORTA as well as contract research by the Dutch public broadcaster NPO (Nederlandse Publieke Omroep). TraPIST was a project co-funded by iMinds, a digital research institute founded by the Flemish Government. Project partners were Televic Rail, Be-mobile, Digitopia, TreinTramBus (all with project support from IWT) and NMBS/ SNCB. AORTA was a project also co-funded by iMinds. Project partners were Televic Healthcare, General Hospital Maria Middelares, Xperthis, Hospital Network Antwerp (ZNA) with project support from VLAIO. Fernanda Chocron Miranda was funded through the project "Comparative matrix of qualitative research with digital technology users", approved for the 2nd Call of the International Cooperation Program (PGCI, Edital n. 02/2015) funded by the Brazilian development agency CAPES. The project involves researchers from the Federal University of Pará (UFPA) and the Federal University of Rio Grande do Sul (UFRGS) - both located in Brazil - as well as from KU Leuven (Belgium). 


\section{Notes}

1. https://en.wikipedia.org/wiki/Pictionary

2. https://en.wikipedia.org/wiki/Cluedo

3. https://boardgamegeek.com/boardgame/13972/party-co

\section{References}

Arnab, S., \& Clarke, S. (2017). Towards a trans-disciplinary methodology for a game-based intervention development process: Towards a trans-disciplinary methodology. British Journal of Educational Technology, 48(2), 279-312. doi:10.1111/bjet.12377

Arrasvuori, J., Boberg, M., Holopainen, J., Korhonen, H., Lucero, A., \& Montola, M. (2011). Applying the PLEX framework in designing for playfulness. In Proceedings of the 2011 Conference on Designing Pleasurable Products and Interfaces - DPPI'11 (p. 1). Milano, Italy: ACM Press. doi:10.1145/2347504.2347531

Bernhaupt, R., Weiss, A., Obrist, M., \& Tscheligi, M. (2007). Playful probing: Making probing more fun. In C. Baranauskas, P. Palanque, J. Abascal, \& S. D. J. Barbosa (Eds.), Humancomputer interaction - INTERACT 2007 (Vol. 4662, pp. 606-619). Berlin, Heidelberg: Springer. doi:10.1007/978-3-540-74796-3_60

Bleumers, L. (2013). Capturing context: Mobile and pervasive game-play in participatory sensing. In K. Mitgutsch, S. Huber, H. Rosenstingl, M. Wagner, \& J. Wimmer (Eds.), Context matters! Exploring and reframing games in context: Proceedings of the 7th Vienna Games Conference FROG 2013 (pp. 168-180). Wien, Austria: New Academia Press.

Blythe, M., Steane, J., Roe, J., \& Oliver, C. (2015). Solutionism, the game: Design fictions for positive aging. In Proceedings of the 33rd Annual ACM Conference on Human Factors in Computing Systems - CHI '15 (pp. 3849-3858). Seoul, Republic of Korea: ACM Press. doi: $10.1145 / 2702123.2702491$

Brandt, E. (2006). Designing exploratory design games: A framework for participation in participatory design? In Proceedings of the Ninth Conference on Participatory Design Expanding Boundaries in Design - PDC '06 (Vol. 1, p. 57). Trento, Italy: ACM Press. doi:10.1145/1147261.1147271

Calvillo Gámez, E. H., Cairns, P., \& Cox, A. L. (2009). From the gaming experience to the wider user experience. In Proceedings of the 23rd British HCI Group Annual Conference on People and Computers: Celebrating People and Technology (pp. 520-523). Swinton, UK: British Computer Society. Retrieved from http://dl.acm.org/citation.cfm?id=1671011.1671078

Cosma, G., Shopland, N., Battersby, S., Seymour-Smith, S., Pockley, A. G., Archer, M., \& . . .Brown, D. (2015). Co-design of a prostate cancer serious game for African Caribbean men. In 2015 International Conference on Interactive Technologies and Games (pp. 7175). Nottingham, UK: IEEE. doi:10.1109/iTAG.2015.20

De Bono, E. (1985). Six thinking hats: An essential approach to business management. Boston, MA: Little, Brown.

De Roeck, D. A. J., Slegers, K., Stappers, P. J., \& Standaert, A. (2011, June 23). Infusing digital creativity in design, the low fidelity way. Proceedings of the Chi Sparks, Chi Nederland, Arnhem. Retrieved from http://resolver.tudelft.nl/uuid:79878004-70e2-4b9d-951bc620a11c8d5e

Furnham, A., \& Yazdanpanahi, T. (1995). Personality differences and group versus individual brainstorming. Personality and Individual Differences, 19(1), 73-80. doi:10.1016/0191-8869(95)00009-U 
Gee, J. P. (2007). What video games have to teach us about learning and literacy. Second edition: Revised and updated edition (2nd ed.). New York, NY: St. Martin's Griffin.

Halskov, K., \& Dalsgård, P. (2006). Inspiration card workshops. In Proceedings of the 6th ACM Conference on Designing Interactive Systems - DIS '06 (p. 2). University Park, PA: ACM Press. doi:10.1145/1142405.1142409

Huyghe, J., Nouwen, M., \& Vanattenhoven, J. (2016). Involving end-users in game based ideation: A case study in hospital logistics. In Proceedings of the 9th Nordic Conference on Human-Computer Interaction - NordiCHI '16 (pp. 1-4). Gothenburg, Sweden: ACM Press. doi:10.1145/2971485.2971488

Huyghe, J., Wouters, N., Geerts, D., \& Vande Moere, A. (2014). LocaLudo: Card-based workshop for interactive architecture. In Proceedings of the Extended Abstracts of the 32nd Annual ACM Conference on Human Factors in Computing Systems - CHI EA '14 (pp. 1975-1980). Toronto, Ontario, Canada: ACM Press. doi:10.1145/2559206.2581348

Kultima, A., Niemelä, J., Paavilainen, J., \& Saarenpää, H. (2008). Designing game idea generation games. In Proceedings of the 2008 Conference on Future Play Research, Play, Share - Future Play '08 (p. 137). Toronto, Ontario, Canada: ACM Press. doi:10.1145/1496984.1497007

Lucero, A., Dalsgaard, P., Halskov, K., \& Buur, J. (2016). Designing with cards. In P. Markopoulos, J.-B. Martens, J. Malins, K. Coninx, \& A. Liapis (Eds.), Collaboration in creative design (pp. 75-95). Cham, Switzerland: Springer. doi:10.1007/978-3-319-2915505

Mitgutsch, K., \& Alvarado, N. (2012). Purposeful by design?: A serious game design assessment framework. In Proceedings of the International Conference on the Foundations of Digital Games - FDG '12 (p. 121). Raleigh, NC: ACM Press. doi:10.1145/2282338.2282364

Mitgutsch, K., Schirra, S., \& Verrilli, S. (2013). Movers and shakers: Designing meaningful conflict in a tablet-based serious game. In CHI '13 Extended Abstracts on Human Factors in Computing Systems on - CHI EA '13 (p. 715). Paris, France: ACM Press. doi:10.1145/2468356.2468482

Muller, M. J. (2002). Participatory design: The third space in HCI. In J. A. Jacko \& A. Sears (Eds.), The human-computer interaction handbook (pp. 1051-1068). Hillsdale, NJ: Lawrence Erlbaum. Retrieved from http://dl.acm.org/citation.cfm?id=772072.772138

Mumford, M. D., \& Gustafson, S. B. (1988). Creativity syndrome: Integration, application, and innovation. Psychological Bulletin, 103(1), 27-43. doi:10.1037/0033-2909.103.1.27

Oh, J., Oh, S. B., Moon, J., Yoo, J. E., Kim, D., Doh, Y. Y., \& Shi, C. (2013). Smart Icebreaker: Basic design for a serious game that promotes intimacy among group members. In Proceedings of the 12th ACM SIGGRAPH International Conference on Virtual-Reality Continuum and Its Applications in Industry - VRCAI'13 (pp. 299-302). Hong Kong: ACM Press. doi:10.1145/2534329.2534373

Ross, A. M., Fitzgerald, M. E., \& Rhodes, D. H. (2014). Game-based learning for systems engineering concepts. Procedia Computer Science, 28, 430-440. doi:10.1016/j. procs.2014.03.053

Schmidt, R., Scheja, S., Lam, T. T., \& Masuch, M. (2015). Anxiety storm: Creating a playful prevention program against performance anxiety in primary school. In Proceedings of the 14th International Conference on Interaction Design and Children - IDC '15 (pp. 251254). Boston, MA: ACM Press. doi:10.1145/2771839.2771889

Sernani, P., Dalpiaz, F., Dragoni, A. F., \& Brinkkemper, S. (2015). Smart tales: An awareness game for ambient assisted living. In B. De Ruyter, A. Kameas, P. Chatzimisios, \& I. 
Mavrommati (Eds.), Ambient intelligence (Vol. 9425, pp. 187-204). Cham, Switzerland: Springer. doi:10.1007/978-3-319-26005-1_13

Slegers, K., Ruelens, S., Vissers, J., \& Duysburgh, P. (2015). Using game principles in UX research: A board game for eliciting future user needs. In Proceedings of the 33rd Annual ACM Conference on Human Factors in Computing Systems - CHI '15 (pp. 1225-1228). Seoul, Republic of Korea: ACM Press. doi:10.1145/2702123.2702166

Warr, A., \& O'Neill, E. (2005). Understanding design as a social creative process. In Proceedings of the 5th Conference on Creativity \& Cognition - C\&C '05 (p. 118). London, England: ACM Press. doi:10.1145/1056224.1056242

Wolf, M., \& Lenz, L. (2014). The economic effectiveness of serious games in the healthcare environment - Application and Evaluation of the Comparative Transformation Model (CTM). In 2014 IEEE 3rd International Conference on Serious Games and Applications for Health (SeGAH) (pp. 1-8). Rio de Janeiro, Brazil: IEEE. doi:10.1109/SeGAH.2014.7067089

\section{Author Biographies}

David Geerts is research manager of the Meaningful Interactions Lab (Mintlab) at the faculty of Social Sciences of KU Leuven (Belgium), affiliated with imec. His research interests include social interactive television and novel human-centered design methods.

Contact: david.geerts@kuleuven.be

Marije Nouwen is a researcher at the Meaningful Interactions Lab (Mintlab). She is pursuing a $\mathrm{PhD}$ degree in social sciences on the topic of remote tangible interactions between dislocated grandparents and grandchildren.

Contact: marije.nouwen@kuleuven.be

Evert van Beek has a background in Industrial Design Engineering from Delft University of Technology and has a special interest in Human-Computer Interaction and user involvement in design processes.

Contact: evertvanbeek@gmail.com

Karin Slegers is assistant professor at KU Leuven and Tilburg University, where she teaches and performs research about new research methodologies in human-computer interaction.

Contact: k.slegers@uvt.nl

Fernanda Chocron Miranda is a $\mathrm{PhD}$ student in Communication and Information, pursuing a joint doctorate at the Federal University of Rio Grande do Sul (UFRGS - Brazil) and KU Leuven (Belgium).

Contact: nandachocron@gmail.com

Lizzy Bleumers works at imec-SMIT-VUB, where she is responsible for living lab projects related to gaming, learning and participatory practice.

Contact: Lizzy.Bleumers@vub.be 